\title{
Determination of the effect of self-care based on the need for quality of life in people with AIDS
}

\author{
Ali Hassanpourdehkordi ${ }^{1}$, Shahriar Salehitali ${ }^{2}$, Soleiman Kheiri ${ }^{3}$, Mariyam Ahmadi $^{4}$, Elham Shahriary ${ }^{5}$ \\ ${ }^{1}$ Social Determinates of the Health Research Center, School of Allied Medical Science, Shahrekord University of Medical Sciences, \\ Shahrekord, Iran \\ ${ }^{2}$ Community-Oriented Nursing Midwifery Research Center, Nursing and Midwifery College, Shahrekord University of Medical \\ Sciences, Shahrekored, Iran \\ ${ }^{3}$ Modeling in Health Research Center, Shahrekord University of Medical Sciences, Shahrekord, Iran \\ ${ }^{4} \mathrm{Al}-Z$ Zahra Hospital, Isfahan University of Medical Sciences, Isfahan, Iran \\ ${ }^{5}$ Voluntary Counselling Centres, Isfahan University of Medical Sciences, Isfahan, Iran
}

\begin{abstract}
Introduction: Considering the prevalence of acquired immunodeficiency virus infection and the need to strengthen programs for improving quality of life, the present study was conducted to examine the effect of self-care based on the need for quality of life in people with acquired immunodeficiency syndrome (AIDS).

Material and methods: In a clinical trial study, 66 human immunodeficiency virus (HIV)-positive patients referred to Navab Safavi Hospital in Isfahan were assigned to two intervention and control groups randomly. The first group was placed under the intervention of self-care program and no intervention was performed in the second group. The quality of life score of patients before and after the intervention in the two groups was examined and compared.

Results: The mean quality of life score in the intervention group was $68.7 \pm 11.8$ before and reached $79.7 \pm 10.3$ after intervention, which was statistically significant $(p=0.002)$. In the control group, the mean quality of life scores before and after treatment were $65.7 \pm 11.9$ and $60.8 \pm 11.7$, respectively, which was not statistically significant $(p=0.053)$. Also, the change in the quality of life score was statistically significant $(p<0.001)$ between case and control groups.

Conclusions: Providing self-care programs in patients with HIV leads to an increase in the quality of life in them. Since these patients are at risk for various types of psychiatric disorders, they must be mentally and emotionally supported and should be encouraged to improve their quality of life by promoting their own self-care programs. Medical science and doctors may find the findings useful in their medical experience and practice.
\end{abstract}

HIV AIDS Rev 2019; 18, 4: 261-266 DOI: https://doi.org/10.5114/hivar.2019.88534

Key words: self-care, quality of life, acquired immune deficiency virus.

Address for correspondence: Maryam Ahmadi, Mscn, Bscn, Al-Zahra Hospital, Isfahan University of Medical Sciences, Isfahan, Iran, e-mail: 250153@gmail.com
Article history:

Received: 20.10.2018

Received in revised form: 18.12 .2018

Accepted: 20.12.2018

Available online: 20.05.2019
International Journal of HIV-Related Problems

HIV \& AIDS R e v i e w 


\section{Introduction}

Self-care involves the ability of individuals to carry out self-care activities and is a learnable behavior that the patient is able to address somewhat depending on their care needs [1-3]. Self-care improves compliance with the disease, and patients can be involved in controlling the complications of the disease. The goal of self-care is helping patients improve their care [4]. Performing this program requires the identification of patients' needs, evaluation of the potential for self-care, acceptance of care skills education and ultimately improves the quality of life [5]. Considering the prevalence of acquired immunodeficiency virus infection and the need to strengthen programs for improving quality of life, the present study was conducted to examine the effect of self-care based on the need for quality of life in people with acquired immunodeficiency syndrome (AIDS).

Today, self-care has been considered by many researchers in the field of medicine, in which the self-care effects on the quality of life of people with certain chronic diseases, such as diabetes, have been studied [6-8]. But in patients with AIDS, unfortunately, care has not been taken seriously, given that today AIDS is a global epidemic, and with the advances in drug therapy [9]. It is still one of the leading causes of mortality in the world. Implementing and strengthening psychosocial support programs for these patients is one of the most important health priorities in many parts of the world. On the other hand, health coverage in the Eastern Mediterranean region for people with human immunodeficiency virus is low and Iran is also in this region [10]. According to a World Health Organization (WHO) report, Iran is one of the countries at high risk of human immunodeficiency virus (HIV) infection and by 2020, the rate of HIV infections in Iran will be 10\% [11].

To control this hygiene, social and cultural challenge, it seems that we should seek to change the behavior of the affected individuals and those with high-risk behaviors in the community [12]. Chronic disease especially HIV has a severe negative impact on the quality of life, mental health and the economic situation of the community [13-15] and families with AIDS $[16,17]$ and neglecting the lives of AIDS patients, lack of proper social status, acquiring a social stigma [18], etc., makes these patients be involved in irresponsible behaviors that lead to the spread of the virus and infection of large numbers of people in the community [19]. Considering the above-mentioned issues, in order to improve the quality of life, we must seek to reduce the social, health, cultural and economic problems of AIDS patients, and this cannot be achieved except by the efforts of all people in the community, especially the healthcare team that through appropriate treatment and gaining the confidence of these patients and organizing classes and study sessions, understands their problems so that patients feel that the community values them and they are treated like other patients, they can learn and can identify their problems and get guidance. The WHO has recently highlighted self-care and quality of life in chronic patients [20]. Unfortunately, self-care has been neglected in HIV/AIDS-infected patients [10]. Therefore, the present study was conducted to determine the effect of a self-care program based on the need for quality of life in people with HIV.

\section{Material and methods}

\section{Design}

The population of the study consisted of HIV-positive patients referring to Navab Safavi Hospital in Isfahan. This is a clinical trial study with a control group that was conducted in Isfahan province in 2016. The study took the approval number, IR.SKUMS. Rec. 1395.44 from the Ethical Committee of Sharekord University. The inclusion criteria for the study included HIV infection, patient consent to study, age over 15 , and communication power. It was also considered that withdrawal of the person during the study, the death of the participant, the occurrence of physical or psychological problems such that the person was unable to cooperate, the lack of participation in the specified sessions and failure to answer the questionnaire questions were considered as criteria for exclusion.

The method of implementation of the plan was that after obtaining permission from the university's medical ethics committee, $66 \mathrm{HIV}$-positive patients referred to the Navab Safavi in the city of Isfahan in southern Iran clinic were selected and assigned to two groups based on random allocation rule (33 people every group). Patients in the intervention group underwent self-care training sessions and the second group was under the routine care programs of the center.

\section{Data gathering}

WHOQOL-BREF is a questionnaire with 26 question that measure overall and general quality of life of a person. This scale was developed by a group of experts from the WHO in 1996 and adjusted from the form of a questionnaire with 100 questions. The questionnaire has four subscales comprising physical health, mental health, social relationships, environmental health and a general score. Initially, a raw score is obtained for each subscale, which must be converted to a standard between 0 and 100 through a formula. A higher score indicates a higher quality of life. The reliability of the WHO's Quality of Life questionnaire in the Nojoomi study with Cronbach's a was 93\% [21] and in the Haidari study with Cronbach's a was 95\% [22]. Initially, the objectives of the plan was explained to the patients, and after obtaining their consent to participate in the study, written consent was obtained from them at the first session then each patient was assigned to a group. After the sample size was completed, both groups of patients and controls were invited to perform the pre-test. It took about 20 days for us to perform the pre-test and each client who participated in the pre-test personally entered the classroom and filled out the quality of life questionnaire in the pres- 
ence of the researcher, during which the questions were read and explained by the researcher and the client ticked the answer. This process continued until the pre-test was done for both the case and control groups. After completing the pretest, the control group continued to live and did not receive any pamphlets or booklet, and did not attend any class, but the intervention group after completing the pre-test based on the time they were able to attend the class were divided into five groups and they were informed that they had to attend 6 sessions of the Navab Safavi Center for behavioral disorders in order to conduct the research.

\section{Intervention}

Intervention for participants was grouped according to the patients' literacy and comprehension (understanding) and in each group session, 6 to 7 people participated. Before the start of the first session, the medical records of all patients were studied. Some of the patients' problems were extracted through the record files. The intervention was completed during 6 sessions of 30 to 45 minutes and once every two days $[23,24]$. At the first session, patients were asked to talk about their illness, and were asked to provide each person with information and an opinion on AIDS. After discussing the above questions and listening to each participant's opinion, they were given educational pamphlets tailored to their literacy and understanding about AIDS and how it was transmitted. The cases which patients felt the need for or it was seen they needed them were recorded and shared with the center's specialists. Patients were told that a solution to some of their problems was presented during the two final sessions with the help of specialists from the center for behavioral disorders of Navab Safavi. In the second to sixth sessions, nutrition topics, AIDS transmission routes, the risks to injecting drug users and sex without protection, drug treatment (medication) and AIDS drug side effects, how to deal with physical and mental health problems and coping strategies with personal problems were raised. At the end of the sessions, all participants were provided with a self-report checklist for each week and tabulated for each topic (nutrition, prevention of transmission to others, side effects of drugs, follow-up of drug orders, oral and pharyngeal care...), and cases which patients need to know were included and the group exposed to self-care, according to their needs. It should be noted that the case group was followed weekly by checklist, and each week, by referring to the Navab Safavi Center, were followed providing a checklist and emphasis on compliance, answering questions and ambiguities in some cases, and received next week's check list, and this procedure was continued completed after 6 weeks and after 6 weeks of intervention, the participants in both case and control groups were visited to assess the effect of self-care intervention, the post-test was performed and after performing the post-test, the control group received pamphlets and training manuals.

\section{Statistical analysis}

Data are shown as means \pm SD for continuous variables and as frequency with percent for categorical variables. The $\chi^{2}$ test was used for comparing categorical variables between groups and the independent $t$-test for continuous ones. The paired $t$-test was used for comparing the change of variables during the study in each group. The parametric repeated measures analysis of variance was applied to test if any change exists among variables during the study between groups. Statistical analysis was done by SPSS 23 and $p$-values $<0.05$ were determined as statistically significant.

\section{Results}

In this study, 66 patients were studied in two groups of 33 intervention and control subjects. During the study period, 3 patients from each group were excluded from the study due to lack of referral and data analysis was performed on 30 subjects in the case group and 30 subjects in the control group. In Table 1 the distribution of demographic

Table 1. Demographic characterization

\begin{tabular}{|c|c|c|c|}
\hline \multirow{2}{*}{ Variable } & \multicolumn{2}{|c|}{ Group } & \multirow{2}{*}{$p$} \\
\hline & Intervention & Control & \\
\hline Age (years) & $38.87 \pm 8.70$ & $39.93 \pm 7.70$ & 0.65 \\
\hline \multicolumn{4}{|l|}{ Gender } \\
\hline Male & $18(60)$ & $18(60)$ & \multirow[t]{2}{*}{1.00} \\
\hline Female & $12(40)$ & $12(40)$ & \\
\hline \multicolumn{4}{|l|}{ Marital status } \\
\hline Single (unmarried) & $6(20.0)$ & $9(30.0)$ & \multirow[t]{4}{*}{0.18} \\
\hline Married & $16(53.3)$ & $18(60.0)$ & \\
\hline $\begin{array}{l}\text { Dead wife/ } \\
\text { husband }\end{array}$ & $4(13.3)$ & $0(0)$ & \\
\hline Divorced & $4(13.3)$ & $3(10.0)$ & \\
\hline \multicolumn{4}{|l|}{ Education level } \\
\hline Elementary & $11(36.7)$ & $6(20.0)$ & \multirow[t]{4}{*}{0.55} \\
\hline Secondary & $11(36.7)$ & $6(20.0)$ & \\
\hline High school & $8(26.7)$ & $10(33.3)$ & \\
\hline University & $2(6.7)$ & $3(10.0)$ & \\
\hline \multicolumn{4}{|l|}{ Employment } \\
\hline Worker & $1(3.3)$ & $2(6.7)$ & \multirow[t]{4}{*}{0.39} \\
\hline Self-employed & $12(40.0)$ & $6(20.0)$ & \\
\hline Housekeeper & $10(33.3)$ & $12(40.0)$ & \\
\hline $\begin{array}{l}\text { Unemployed/ } \\
\text { Retired }\end{array}$ & $7(23.3)$ & (10 (33.3) & \\
\hline \multicolumn{4}{|l|}{ Addiction } \\
\hline Yes & $13(43.3)$ & $14(46.7)$ & \multirow[t]{2}{*}{0.8} \\
\hline No & $17(56.7)$ & $16(53.3)$ & \\
\hline
\end{tabular}


respectively, and the quality of life score in the intervention group was significantly improved, while in the control group, the mean life quality scores before and after treatment were $65.7 \pm 11.9$ and $60.8 \pm 11.6$, respectively, and the difference before and after intervention was not significant. Zandi's study in Tehran in 2002 showed that providing selfcare programs in patients with liver cirrhosis leads to an improvement in the quality of life of patients [23]. Shebon et al. also showed in a study conducted in the United States in 2014 that increasing the life expectancy of people with AIDS and the chronicity of the disease leads to an increase in mental disorders and substance abuse in these patients, so that the quality of life of patients is severely reduced. Patients with acquired immune deficiency virus, due to the social and cultural impacts of AIDS, face many problems in various social, cultural and moral contexts, with the exception of disease problems, and therefore psychological disorders, especially depression, are very common in these patients [19], because, on the one hand, AIDS is a life-threatening disease, and even people with HIV infection are afraid that the infection will turn out to be an obvious illness and stop them. On the other hand, patients with this infection, even if they have not received the infection through sexually transmitted infections, are subject to different charges from different people, and this will result in their rejection from the community. Ultimately, the rejection of people with acquired immunodeficiency virus causes psychological disorders, especially depression and reduced quality of life in them. Hence, mental health care is important in these people. Multivariable analysis indicated negative associations between quality of life and psychological problems, and demands for social and financial support. Interventions focused on psychosocial issues would improve the quality of life for people living with HIV $[10,29,30]$.

The results of the study of Ebachi and Behroan showed that the severe stigma affects the health of the individual and the community, and with the acceptance of these patients in society, the burden of mental illness can be reduced and life satisfaction increases [31]. A study conducted in 2013 in Nigeria showed that people who are supported by the community and the family and have a family background and job have the best status, and those who are rejected from the family are in the worst situation [13]. In relation to psychiatric support there are so many different ways in which one of the best practices is the self-care approach, so that psychological components in people are strengthened so much that sick people themselves take care of their health. In fact, raising self-esteem is considered to be the most important component of self-care programs, but since HIV infection in our country is not as widespread as in other countries, serious measures have not been taken to provide the psychological support of patients with this infection, and so research in this area is limited. With the help of health professionals and educators, we can prevent mental disorders in these patients, thereby reducing the unnecessary health costs and improving the quality of life [19]. Confirming this, the study by Kim et al. showed that nursing intervention should be focused on providing interactive communication and emotional social support to improve self-management and health-related quality of life of people living with HIV [29]. However, another study showed the relationship between housing stability and HIV self-management in women with this condition [32].

\section{Conclusions}

Providing self-care programs in HIV patients has led to an increase in the quality of life in them and more satisfaction in patients. Therefore, since HIV-positive patients are at risk for various types of psychiatric disorders, especially depression, for various personal and social reasons, and the progression of these disorders will lead to suicide or refusal to be treated and even attempts to transmit the disease to others, it is necessary that the patients undergo psychological and emotional counseling during scheduled training, along with health care and treatment and by promoting self-care programs in them, for their quality of life to be improved.

\section{Acknowledgements}

We thank the Research and Technology Deputy of Shahrekord University of Medical Sciences. The study took the approval number, IR. 1394.301 from the Ethical Committee of Shahrekord University of Medical Sciences.

\section{Conflict of interest}

The authors declare no potential conflicts of interest with respect to the research, authorship, and/or publication of this article.

\section{References}

1. HassanpourDehkordi A, Mohammadi N, NikbakhatNasrabadi A. Hepatitis-related stigma in chronic patients: a qualitative study. Appl Nurs Res 2016; 29: 206-210.

2. Mohammadi N, HassanpourDehkordi A, NikbakhatNasrabadi A. Iranian patients with chronic hepatitis struggle to do self-care. Life Sci J 2013; 10: 457-462.

3. Wilson FL, Baker LM, Nordstrom CK, Legwand C. Using the teachback and Orem's Self-care Deficit Nursing theory to increase childhood immunization communication among low-income mothers. Issues Compr Pediatr Nurs 2008; 31: 7-22.

4. Riegel B, Jaarsma T, Strömberg A. A middle-range theory of selfcare of chronic illness. Adv Nurs Sci 2012; 35: 194-204.

5. Manzini FC, Simonetti JP. Nursing consultation applied to hypertensive clients: application of orem's self-care theory. Rev Lat Am Enfermagem 2009; 17: 113-119.

6. Afsar Kazeroni P, Khazaei Z, Mousavi M, Khazaei S, Sohrabivafa M, Dehghani SL, et al. Prevalence of human immunodeficiency virus and tuberculosis among homeless individuals. Immunopathol Persa 2018; 4: e06.

7. Kelishadi R, Djalalinia S, Qorbani M, Mansourian M, Motlagh ME, Ardalan G, et al. Self-rated health and life satisfaction in Iranian children and adolescents at the national and provincial level: the CASPIAN-IV study. Iran Red Crescent Med J 2016; 18: e28096.

8. Hovsepian S, Qorbani M, Motlagh ME, Madady A, Mansourian M, Gorabi AM, et al. Association of obesity and health related quality of life in Iranian children and adolescents: the Weight Disorders 
Survey of the CASPIAN-IV study. J Pediatr Endocrinol Metab 2017; 30: 923-929.

9. Kanekar AS. HIV/AIDS counseling skills and strategies: can testing and counseling curb the epidemic? Int J Prev Med 2011; 2: 10-14.

10. Hermez J, Petrak J, Karkouri M, Riedner G. A review of HIV testing and counseling policies and practices in the Eastern Mediterranean Region. AIDS 2010; 24 Suppl 2: S25-S32.

11. Emadi SN, Bhatt SM, Machoki M'Imunya J, Suleh AJ, Raeeskarami SR, Rezai MS, et al. Cutaneous manifestation in children with HIV/AIDS. J Pediatr Rev 2014; 2: 17-28.

12. Dutta A, Wirtz AL, Baral S, Beyrer C, Cleghorn FR. Key harm reduction interventions and their impact on the reduction of risky behavior and HIV incidence among people who inject drugs in low -income and middle-income countries. Curr Opin HIV AIDS 2012; 7:362-368.

13. Folasire OF, Akinyemi O, Owoaje E. Perceived social support among HIV positive and HIV negative people in Ibadan, Nigeria. World J AIDS 2014; 4: 15-26.

14. Galindo-Quintero J, Mueses-Marin HF, Montaño-Agudelo D, Pinzón-Fernández MV, Tello-Bolívar IC, Alvarado-Llano BE, et al. HIV testing and counselling in Colombia: local experience on two different recruitment strategies to better reach low socioeconomic status communities. AIDS Res Treat 2014; 2014: 803685.

15. Kanu NE, Tobin-West CI. Health-related quality of life of HIV patients with and without tuberculosis registered in a Tertiary Hospital in Port Harcourt, Nigeria. HIV AIDS Rev 2018; 17: 210-217.

16. Hajian S. Positive effect of antioxidants on immune system. Immunopathologia Persa 2015; 1: e02.

17. Kafeshani M. Diet and immune system. Immunopatholologia Persa $2015 ; 1$.

18. World Health Organization. Medical eligibility criteria for contraceptive use. World Health Organization, Geneva 2010.

19. Sherbourne CD, Hays RD, Fleishman JA, Vitiello B, Magruder KM, Bing EG, et al. Impact of psychiatric conditions on health-related quality of life in persons with HIV infection. Am J Psychiatry 2000; 157: 248-254.

20. World Health Organization. Regional Office for the Western Pacific. Metrics for monitoring the cascade of HIV testing, care and treatment services in Asia and the Pacific. WHO Regional Office for the Western Pacific, Manila 2014.

21. Nojoomi M, Anbari K. A comparison of the quality of life in HIV/ AIDS patients and control group. Razi Journal of Medical Sciences 2008; 15: 169-176.

22. Heydari A, Jafari F. Compare the quality of life, social support and general health of people infected with AIDS virus than normal people of Ahvaz city. New Findings in Psychology 2009; 2: 47-60.

23. Zandi M, Alavian S, Memarian R, Kazem Nejad A. Assessment of the effect of self care program on quality of life in patients with cirrhosis referred to Tehran hepatitis center in 2003. Razi Journal of Medical Sciences 2004; 11: 411-420.

24. Schneider MC, Castillo-Salgado C, Bacallao J, Loyola E, Mujica OJ, Vidaurre M, et al. Summary of indicators most used for the measurement of the health inequalities. Epidemiol Bull 2005; 26: 7-10.

25. Tesfaye SH, Bune GT. Generalized psychological distress among HIV-infected patients enrolled in antiretroviral treatment in Dilla University Hospital, Gedeo zone, Ethiopia. Glob Health Action 2014; 7: 23882.

26. Fazeli P, Montoya J, McDavid C, Moore D. Older HIV+ and HIVadults provide similar definitions of successful aging: a mixedmethods examination. Gerontologist 2018; 2: 23-29.

27. Holzemer WL, Human S, Arudo J, Rosa ME, Hamilton MJ, Corless I, et al. Exploring HIV stigma and quality of life for persons living with HIV infection. J Assoc Nurses AIDS Care 2009; 20: 161-168.

28. Shahreza FD. From oxidative stress to endothelial cell dysfunction. J Prev Epidemiol 2016; 1: e04.
29. Kim GS, Kim S, Choi JY, Lee JI, Park CG, McCreary LL. Mediators and moderators of health-related quality of life in people living with HIV. J Assoc Nurses AIDS Care 2018; 29: 580-591.

30. Lindayani L, Chen YC, Wang JD, Ko NY. Complex problems, care demands, and quality of life among people living with HIV in the antiretroviral era in Indonesia. J Assoc Nurses AIDS Care 2018; 29: 300-309.

31. Abachi A, Behravan H. The analysis of stigma impact on quality of life in patients with HIV/AIDS: a phenomenological study. J Qual Res Health Sci 2013; 2: 158-172.

32. Webel AR, Higgins PA. The relationship between social roles and selfmanagement behavior in women living with HIV/AIDS. Womens Health Issues 2012; 22: e27-e33. 